\title{
The Agri-Foodstuffs Market and the Value Chain: Proposals for an Integrated System of Multifunction Logistic Centres in the Metropolitan City of Reggio Calabria
}

\author{
Maurizio Malaspina ${ }^{1, a}$ \\ ${ }^{1}$ Mediterranea University of Reggio Calabria - PAU - Department of Heritage, Architecture, Urban \\ Planning, Via Salita Melissari - 89124, Reggio di Calabria, Italy \\ amaurizio.malaspina@unirc.it
}

\section{Keywords: Local Development, Productive Districts, Agri-Foodstuffs Industry, Logistics.}

\begin{abstract}
The study investigates the agri-foodstuffs market, highlighting the developments of the last decades that have seen the large-scale retail trade to exert an action more and more invasive in the distribution value along the line characterizing the production chain.

We focused on the Province of Reggio Calabria, its scenario of metropolitan city and the agrifoodstuffs chains that configure it as an important area for quality and quantity produced. Finally, it was proposed to overcome the narrow view of wholesale trade, with the hypothesis of a major agricultural hub serving the primary production in the Province of Reggio Calabria and its future metropolitan city, a route outlined by this work in order to revive a field that has always been strategic for the development and dynamics of the local market.
\end{abstract}

\section{Changes and transformations in the agri-foodstuffs market.}

The analysis of value formation processes in the different steps of the sequence characterizing a production chain is extremely important, because on this one depends both the economic advantage lying at the basis of production and the economic benefit of the consumer to get in a supply of the product itself. The two ends of the chain are the balance in determining the price, although not the main component. In fact, in the production of value, the intermediate steps, characterized by brokerage and by logistics and transport services, come into play more and more increasingly. This especially happens in the agri-food sector, characterized by an extremely competitive system. Taking as reference the ISMEA ${ }^{1}$ (Ismea, 2012) elaborations on the value chain in the domestic fruit and vegetables sector, it comes out a process that, backwards, starts from consumptions and from their value, to reach, through several decompositions, the manufacturer. ISMEA applies the Input-Output methodology to determine the added value that is produced step by step, since it is efficacious to create simulated scenarios and then to estimate also impacts of specific segments. In the ISMEA chain come into play the actors of production (farmers), the productions outside the domestic market (foreign productions), the gross margin of distribution (transport and distribution), which also includes indirect taxes paid by the consumer. The ISMEA Value Chain refers to the period between 2000 and 2009, in order to assess the changes in the distribution of value in a remarkable time span. The results highlight that out of $100 €$ spent by consumers, in 2009 it is almost $73 \%$ ( 72,9 euro) to be absorbed by the distribution margin, with data slightingly increasing in comparison with 2000, when it stood at around 68\%. Therefore it clearly emerges the increasingly significant and prevailing weight on the spin-off value of the product of the amount assigned to the wholesale brokers, agents, to retail and transport, plus indirect taxes on the final value of the asset. The farmer, in 2009 intercepted just $11.9 \%$ of the final value of the product, data considerably declining compared with 2000 , when it stood at around $17,5 \%$. Six percentage points less that demonstrate how the production intercepts less and less the increase in value of consumption, dramatically losing bargaining power in the chain, to advantage of intermediaries and logistics. And we have to consider that the percentage intended for the production includes production costs, especially wages and depreciations, which in the period 2000-2009 show a

\footnotetext{
${ }^{1}$ Institute of Services for the Agricultural Market
} 
significant increase, at the expense of operating profits. So, if in 2000 the operating profits stood at around $36 \%$ of the share of the value due to the farmer, in 2009 it falls down to $10,4 \%$. This means that, if in 2000 out of those 100 euros spent by households for foodstuffs, just 7.6 euros remained to the producer, in 2009 the figure drops to 1.5 euros (ISMEA 2012).

The ISMEA study about the value chain in agricultural production highlights, therefore, the increasingly important role of distribution margins in determining the final value of an agri-food product. It is clear that agriculture is the weak link in the system, the one in which inefficiencies and competitive weaknesses concentrate.

\section{The agri-food chain in the province of Reggio Calabria.}

Data concerning the agri-food production chain in the Province of Reggio Calabria, as they emerge from the last ISTAT census surveys of agriculture (2010), have a particularly relevant connotation under different profiles. First of all, under a quantitative profile, with a production figure significant both in terms of acreage and of quantity produced, and a decennial trend that reaffirms, on the whole of primary productions, a significant increase of production $(30,61 \%)$ and of crops $(40,45 \%)$, also considering a significant increase in the Utilized Agricultural Area (Superficie Agricola Utilizzata (SAU)) that leads to a 10,4\% increase. The Total Agricultural Surface, on the contrary, consistently reduces $(-8,3 \%)$ and the company average size increases, with one SAU per firm, that, even if it remains among the lowest values at regional level, shows a significant increase from 2.4 to 3.3 Ha for company. These data overall show the solidity of the provincial production system, in a period of total consumption crisis, but especially in a period of

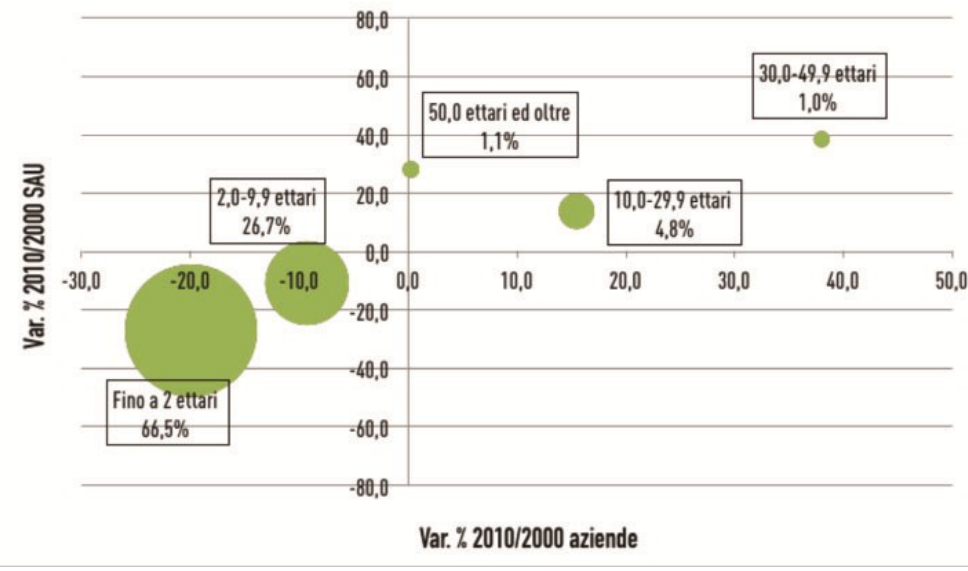

Fig. 1, SAU for farm company, ns. elaboration on ISTAT reorganization of the commercial outlet system.

The most important crop, in terms of quantity, in the production system of the Province of Reggio Calabria, is citrus, with an average annual quantitative impact in the last decade of $53.28 \%$ on the whole of the harvest and an average quantity of 6.553.669, 17 quintals per year. Citrus is followed by the olive tree, which reaches the annual quantity of $37.26 \%$, with an average of quantities harvested of $4.636 .934,33$ quintals per year.

These two cultures dominate the agri-productive provincial production, absorbing a total of more than $90 \%$ crop product. Crops such as fresh fruit (just $1.58 \%$ ), vegetables $(3.09 \%)$, vine $(1.08 \%)$ and bulb plants $(1.45 \%)$ are not much significant. Altogether the fruit and vegetable products absorb, compared with all the agri-food productions, as much as $99.14 \%$. This is a poorly diversified production system in the culture system, insufficiently flexible to cyclical trends of markets and as such extremely fragile under the competitive profile. Also with regard to support to the sectorial policy, the presence of a nearly monocultural system, determines a point of weakness in the dynamics of expansion of a market that, in spite of the quantities produced, does not meet its own domestic demand.

In the Province of Reggio Calabria, against a significant increase of the utilized agricultural area in the period 2000-2010 there is a marked decline in the number of companies in the primary sector, going from 45.200 of 2000 to 2010 's 36.340 (-19.60\%). It follows an increase in the average enterprise size in relation to the Utilized Agricultural Area, data which confirm the company's size in the food production sector, increasingly strategic for the outlet competitiveness on the markets of goods produced. The farm dimension, according to the report of the utilized agricultural area per holding, moves from an average of 2,40 Ha per holding in 2000 to a dimension equal to $3.30 \mathrm{Ha}$ in 


\section{Produzioni totali}

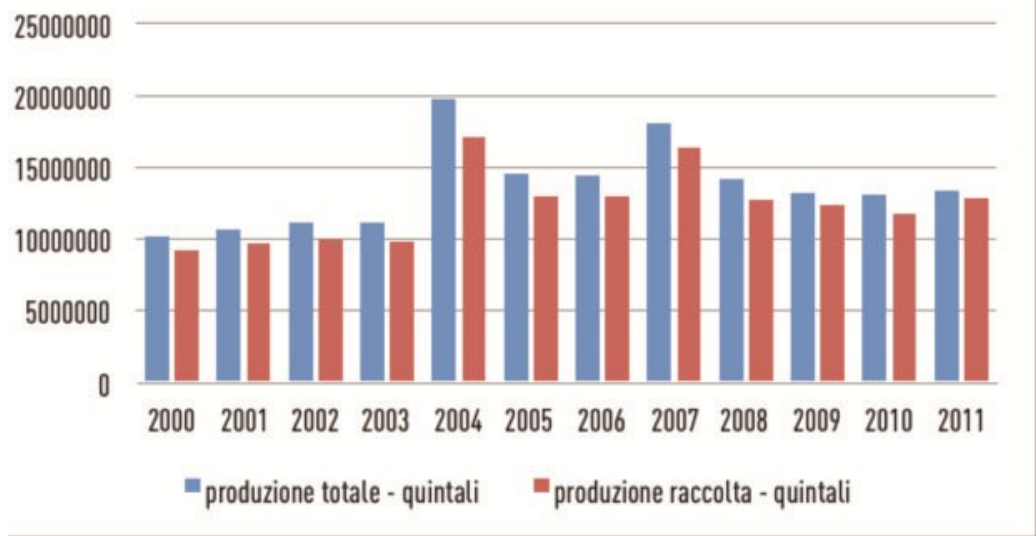

Fig. 2 , Agri-food productions in the province of Reggio Calabria, trend, ns. elaboration on ISTAT data.
2010, with an increase of nearly one hectare on average for holding. This is because, against a slight increase of SAU in this decade, there was a marked decline in farms, as previously highlighted.

While in 2000 the Province of Reggio Calabria covered $25.92 \%$ of the survey of farms in Calabria, in 2010 the data pass to $26.37 \%$, against a regional figure that undergoes a proportional reduction in this decade. Holdings are still predominantly privately owned $(93.2 \%$ in 2000 and $82.3 \%$ in 2010), with a direct management reaching $94.5 \%$ compared with the total of farms surveyed. The family nature of the company management, tied to agricultural production, is also confirmed by the analysis of the legal form of the business system of Reggio Calabria, which consists of $99,2 \%$ individual firms (in line with the regional data, $96.9 \%$, but higher compared with the national one, steady at $85,4 \%$ ). It's largely a question of not yet computerized companies (98.9\%) employing in 2010 a labor of 87.824 units (26.12\% of the entire workforce engaged in agriculture in Calabria), of which $53.4 \%$ men and $46.6 \%$ women. The Province of Reggio Calabria, moreover, has 1.919 holdings with an area planted with organic production, for a utilized agricultural area of $20.906 \mathrm{Ha}$ and an average surface of $10.9 \mathrm{Ha}$ per holding. It is still one of the lowest data nationwide, which suffer from difficulties of investment in product and process innovation expressed by this sector. Finally, data on complementary activities of companies, that still highlight a scarce spread of integration activities to agricultural income, excluding the third-party arrangements (44.3\%). Activities such as agritourism, among the first and most effective complementary activities, activated in Italy with specific reference standards and economical supports, find the Province of Reggio Calabria at the penultimate place in Calabria, with just $15 \%$ companies equipped out of the total of agricultural holdings. Even more contained the spread of activities for the production of energy from renewable sources $(1.1 \%)$, teaching farms $(6.5 \%)$ and processing activities $(15 \%)$.

\section{From the wholesale markets to the "agro-foodstuff city of Reggio Calabria" - multifunctional logistic platform in the metropolitan city of Reggio Calabria.}

Reggio Calabria has a great productive reality, in terms of both good quantities and excellent products recognized by the market. It suffers from an inadequate diversification of supply and from an extremely small and fragmented farm dimension; these characteristics, combined with the difficulty of creating integrated offer networks, determine an extremely weak competitive system.

The trading market founds only partially in the GD a distribution channel, with fruit and vegetables consumption largely focused on specialized and detailed outlets. Combining the dimensional farm condition to a large-scale distribution still poorly invasive, it appears being important the role of wholesale markets as a way for selling off the products. For the enhancement of the agro-food market, especially looking forward to the future of the metropolitan city that will absorb the provincial dimension under the programmatic and strategic point of view, it becomes essential to think in terms of integrated management of the supply chain, starting from the governance process, so that it is able to bring "inside" all the actors producing an added value to the product. On the other hand, it's necessary to start up an investment programme aimed at strengthening the intermediate productions, removing them from the exclusive market of the large- 


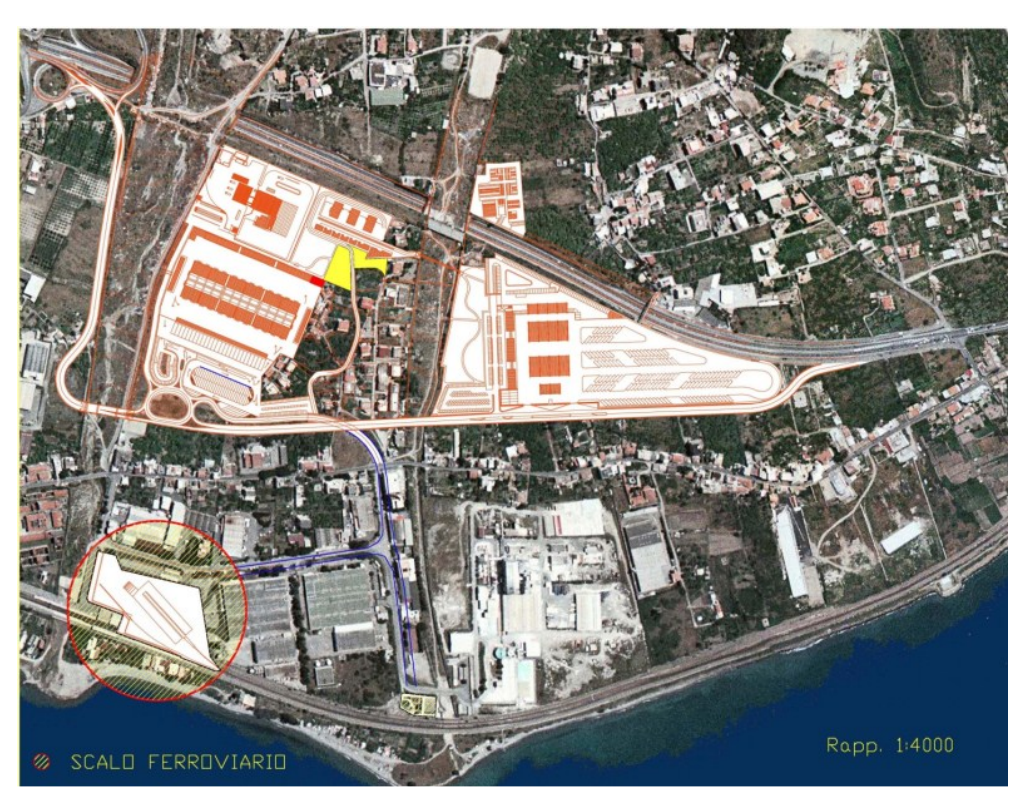

Fig. 3, The new agro-food centre in Mortara, in the south area of Reggio Calabria: project plan. Photo O.R.A. Association.

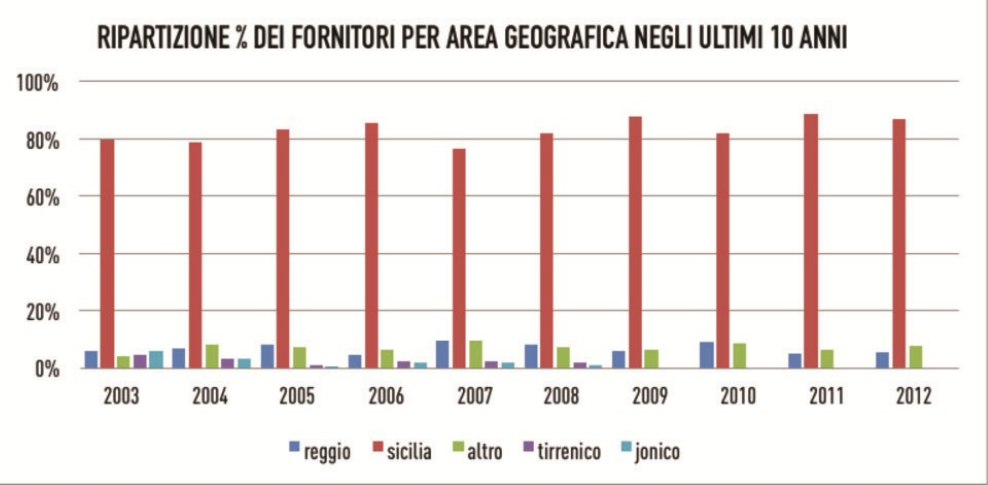

Fig. 4, Origin of suppliers by geographic area. Source: ns. direct detection and elaboration on the basis of sample. scale distribution. From this point of view, the logistics becomes strategic and, as such, it also becomes decisive to endow the coming metropolitan city of Reggio Calabria with a multifunctional polycentric platform allowing the processing of goods, the integrated chain of cold and all other elements representing that added value now entirely pointed out from the distribution. We start from considering that, by constructing the new fruit and vegetables market in Reggio Calabria and, on the whole, by organizing the Mortara agri-food sector/pole (including the municipal slaughterhouse), the decision to not create a multifunctional platform for the first processing of the products, was an extremely disadvantageous mistake. The period was the right one, the early 1990s, when retailing was in an expansive phase but still poorly organized on the territory. Having renounced to the storage functions, to warehousing, to processing and packaging products, for not having considered the necessary spaces and a management structure able of generating economies from the integrated services, was a mistake paid dearly even by those operators in the name of whom was made this choice.

Even in a renewed market structure, that after so many years is not yet completed, the market competitiveness of Reggio Calabria will increasingly decline together to the ability to intercept flows from nearby Sicily (currently $90 \%$ of the supplies arriving to the general markets comes from Sicily) and an alternative distribution organization will gradually develop (of which we already see ample signals). The market is extremely detached from its territory: the operators of the province able to reach a positive outcome in the fruit and vegetable markets of Reggio Calabria are really few, and the ability to intercept large manufacturers is weak, given that they are now oriented to the short chain of the national large-chain distribution.

In an interim stage, it is therefore necessary to reintroduce a polarizing role of the market structure of Reggio Calabria putting it at the service of production as a competitive and effective end market. This means a new model of public-private governance, able to work with a business logic aimed at achieving those objectives moved by productivity. And also by investing in the completion of the market structure, in the integration of those services never took in consideration and by creating at least two more agri-food poles with an integrated management together with Mortara and located in the main productive areas of the Province. The aim is the construction of a polycentric mutifunction logistic centre inside the provincial area, having its managerial functions in Mortara Center but with territorial branches in the Piana of Gioia Tauro (the role of its Port is strategic, now completely 


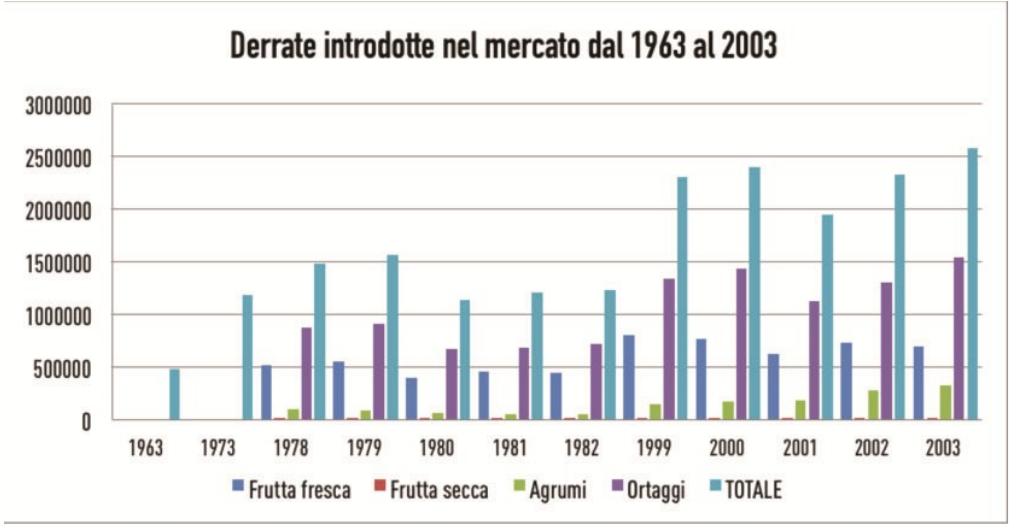

marginal compared to the province's trade flows), and in the area of Locri. The "Agri-food city of Reggio Calabria" must be conceived as a physical door disposed to the entry and distribution of Reggio Calabria goods from and to the Countries of the Mediterranean basin, therefore strengthening the hinge role between the European channels and the internal areas that the territory of Reggio Calabria can play.

Fig. 5, Trend of incoming goods at fruit and vegetable markets in Reggio Calabria. Source: Associated Markets Association of Agri-Food Markets Wholesale.

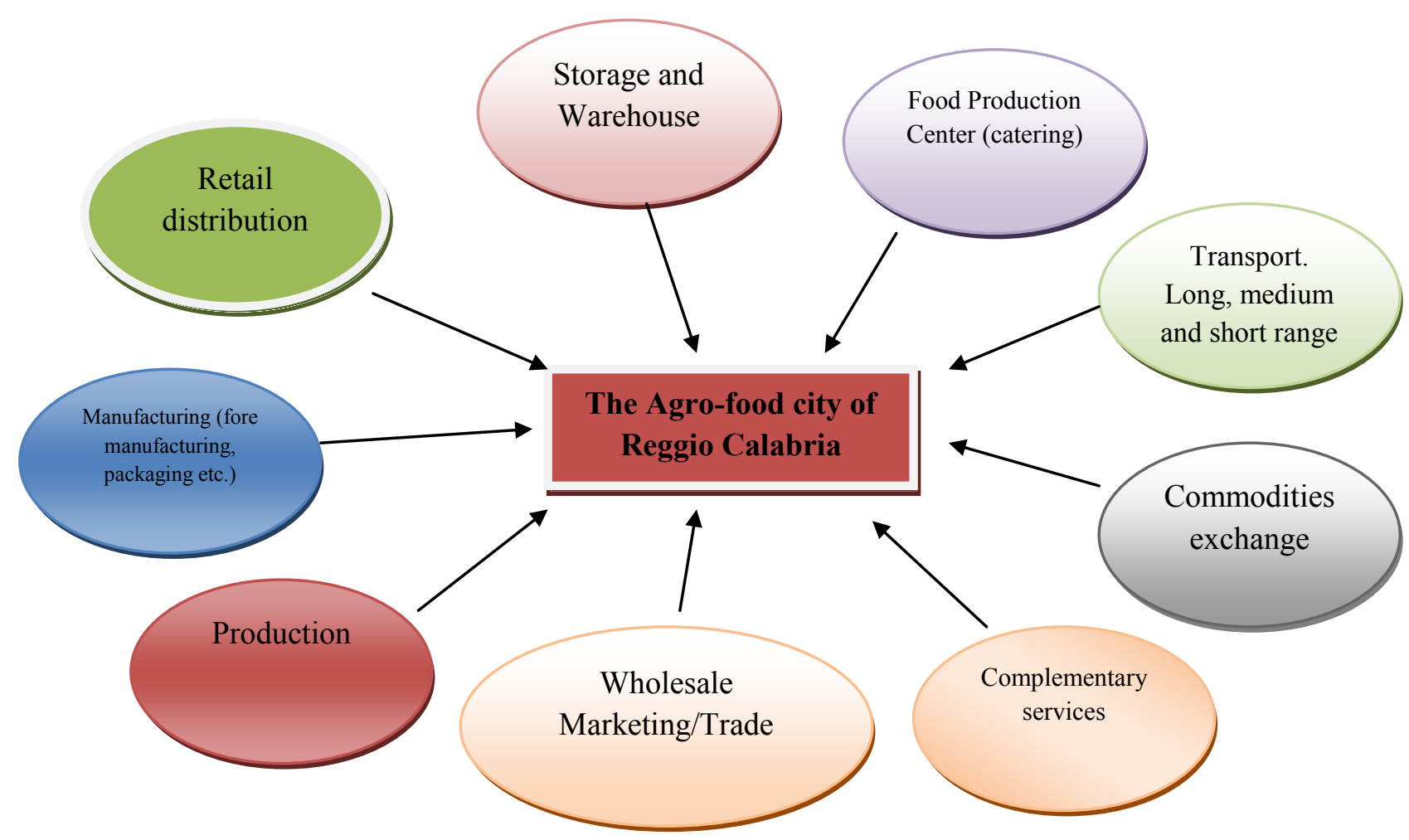

Fig. 6, The integrated functions from the Agri-food project of Reggio Calabria city. Our project processing.

The wholesale fruit and vegetables markets and the fish and meat ones, will operate in the Agrifood city of Reggio Calabria deployed on the area of the province, together with a complex of modern storage and preservation facilities of perishable products. The "Agri-food city of Reggio Calabria" must base its mission on the concept of multi-purpose goods (completeness of the food range) and functional (simultaneous presence of structures having all commercial and service functions that operate in food, trade and catering distribution, in community supply and in retail and 
wholesale distribution). The agri-food platforms must be designed as a systemic process, capable of ensuring the primary services, such as transport and storage, as well offering an integrated set of functions able to provide a competitive advantage to the operators and the territory who will benefit. Therefore new logistical functions such as the preservation, the storage of goods, the processing, but at the same time the integrated marketing and distribution, the promotion, the marketing, the research for development and innovation. Next to "core" activities, a series of complementary and strategic functions to make the "Agro-food city of Reggio Calabria" an open space to the city and the territory, with specialized retail outlets, zero-miles restaurants and specialized functions.

The ability of the project to provide new outlets to the agri-food products of the province, focuses on the logistics functions of marketing. We aim at the introduction of a commodity exchange formerly envisaged in the Mortara project, at the creation of fairs (of which the province of Reggio Calabria is practically devoid), maintaining the wholesale of fruit and vegetables and by transferring that one of the fish. These functions will attract economies, from the identification of spaces and services, together with the deployment that will consider an intermodal logistics platform for the Large-Scale Retail Channel, and a carriers fleet for provincial and local distribution. Inside the managerial center of Mortara, we will create a promotional and marketing structure for the diffusion of policies of the product, as well as a research and innovation division.

The restaurants will be a major vein, with the production of catering meals as innovative function for a large area such as the one proposed by the project. Finally the related services, the zero-miles restaurants, the canteen for operators, bar and other functional services for the business activities, will suggest the "Agri-food city of Reggio Calabria" as a space opened to the whole territory and, to the accurate consumer, will offer an incentive to mend an important relation with the land and its products.

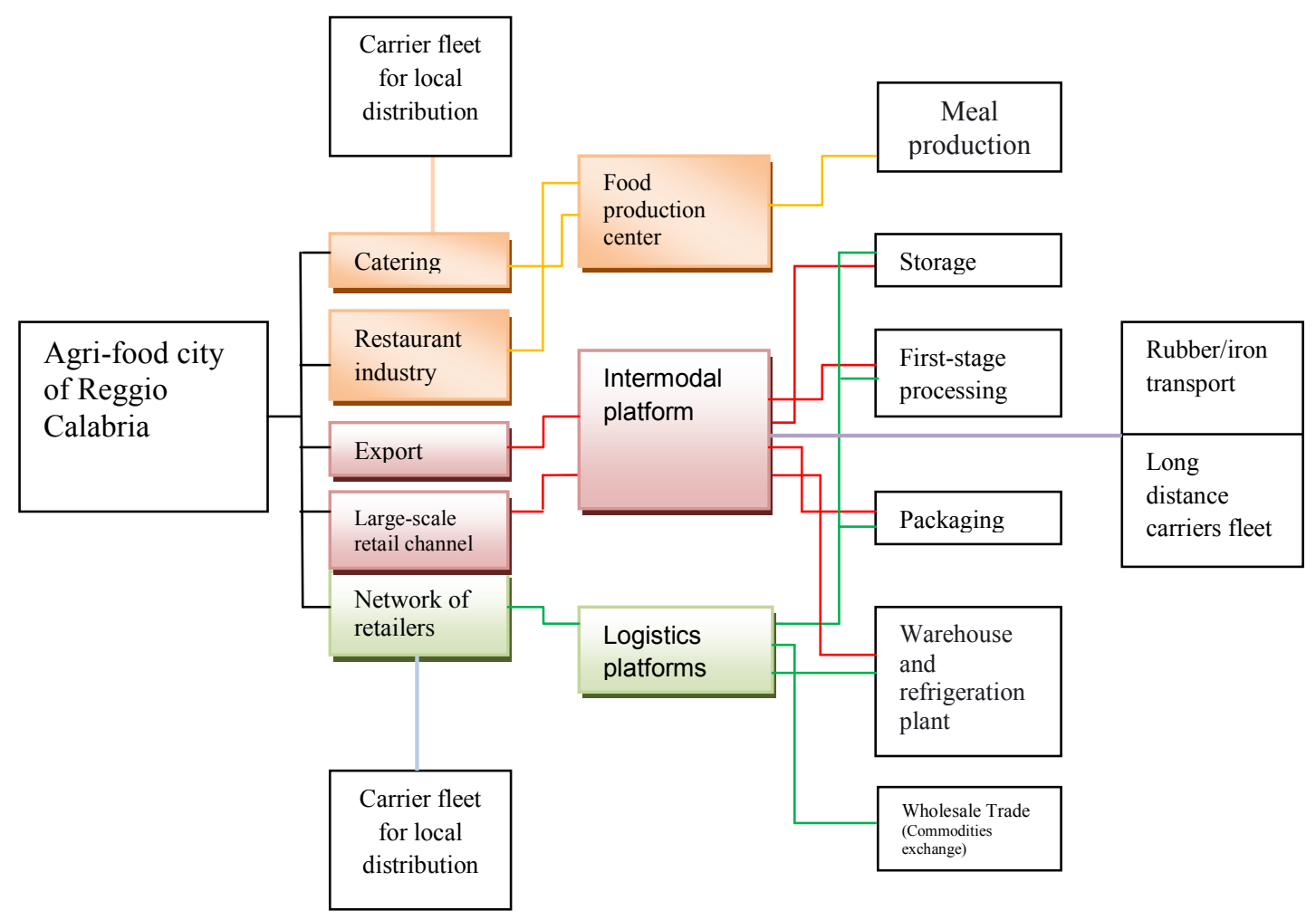

Fig. 7, The Agri-food city of Reggio Calabria: Functional organization of the productive chain. 


\section{Conclusions}

The study, based on the analysis of the agro-food market and on its evolutions, drew up a proposal for a reorganization of the provincial markets, overcoming the narrow vision of wholesale agro-food market, assuming the birth of a large integrated management pole of the markets in the future metropolitan city of Reggio Calabria. The strategic proposal considers the setting up/creation of the "Agri-food city of Reggio Calabria" a polycentric system of multifunctional platforms, with an integrated public-private management, with regional nodes in the major provincial production contexts, allowing storage, manufacture of goods, the cold chain, integrated handling and marketing of agricultural products in the province of Reggio Calabria, creating an added value for the goods and a greater competitiveness on the markets for Reggio Calabria products.

Imagining an hypothesis of management for the "Agri-food city of Reggio Calabria", the reference is clearly aimed at creating a consortium for actions at public-private participation that:

a) Manages in an integrated manner those activities characterizing the core-business of the "Agri-food city of Reggio Calabria";

b) Administers the relationships with the suppliers and the demand coming from the local, national and international markets;

c) Is organized as a dealer of some outsourced services;

d) Identifies the integrated marketing channels of the manufactured/processed product;

e) Organizes the marketing program to promote the agri-food sector through commercial ventures and area events.

To get to the management company it will be necessary to start a shared and participative path for the construction of the industrial plan which, from one hand, it implements the completion of Mortara plants of those structures formerly started and functional; from the other hand it defines the strategies to enable investments for the realization of integrated logistics platforms and to reach the markets thanks to/through an articulated and attractive offer.

\section{References}

[1] A. Andriano: Produzione e Logistica, Franco Angeli, Milano (1995)

[2] G. Becattini: Distretti industriali e Made in Italy, Bollati-Boringhieri, Torino (1998)

[3] A. Bertazzoli, C. Giacomini, G. Petriccione (a cura di): Il sistema ortofrutticolo italiano di fronte ai nuovi scenari competitivi, Studi \& Ricerche Inea, Edizioni Scientifiche Italiane, Napoli (2004)

[4] G.P. Cesaretti, R. Green: Organizzazione della filiera ortofrutticola. Esperienze internazionali a confronto, Franco Angeli, Milano (2006)

[5] F. Dallari, G. Marchet: La logistica che cambia. Progettazione, gestione e controllo del processo logistico d'impresa, Il Sole 24 Ore, Milano (2006)

[6] F. Dallari, G. Marchet: Outsourcing logistico nel settore del largo consumo, Il Sole 24 Ore, Milano (2008)

[7] A. Fearne, D. Hughes: Success Factors in the Fresh Produce Supply Chain: Some Examples from the UK. Executive Summary. London, Wye College (1996)

[8] Ismea, Outlook dell'agroalimentare italiano - Rapporto annuale, Roma (2008)

[9] Ismea, Check Up 2012, La competitività dell'agroalimentare italiano, Roma (2012)

[10] Istat, $6^{\circ}$ Censimento Generale dell'Agricoltura (2010)

[11] Istat, $15^{\circ}$ Censimento generale della popolazione e delle abitazioni (2010)

[12] Istat, Censimento dell'industria e dei servizi (2011)

[13] B. Luceri: La logistica Integrata, Giuffrè, Milano (1996) 
[14] G. Marotta, M.A. Perito: Canali distributivi e modelli organizzativi: una prospettiva di sviluppo per i mercati ortofrutticoli all'ingrosso, in Rivista di Economia Agraria, fascicolo 3, volume 55, (2000), pp. 409-438

[15] E. Mollica, M. Malaspina: Programmare, valorizzare e accompagnare lo sviluppo locale, Laruffa, Reggio Calabria (2012)

[16] M. Malaspina: Il mercato ortofrutticolo della provincia di Reggio Calabria e la catena del valore collegata ai mercati generali di Reggio Calabria, Laruffa, Reggio Calabria (2014) 